\title{
Gellability zone for aluminium alkoxides
}

\author{
Manoj M. Haridas, Jayesh R. Bellare* \\ Microstructure Engineering and Ultramicroscopy Laboratory, Department of Chemical Engineering, Indian Institute of Technology, Powai, \\ Mumbai 400 076, India
}

\begin{abstract}
Ethyl acetoacetate modified aluminium sec-butoxide can be hydrolysed and gelled with alkaline, neutral or acidic media within a $\mathrm{pH}$ range of 3.0-8.5. Alumina precipitation occurs if $\mathrm{pH}$ values at any point in the sol-gel transition are outside this range. Nine different gelling agents have been evaluated for $\mathrm{pH}$ dependence of gel point. Based on stoichiometric considerations, only those systems with a $\mathrm{pH}$ of 5.7-7.7 at their gel points can be fully hydrolysed before gelling and the extent of hydrolysis is reduced with an increase in the acidity/basicity of the system. In $\mathrm{NaOH} / \mathrm{HNO}_{3}$ hydrolysed precursors, the extent of hydrolysis at the gel point is about $55 \%$. An unhydrolysed precursor has a $\mathrm{pH}$ of 6.4 which increases rapidly as aluminium hydroxide formation begins and a $\mathrm{pH}$ of 5.7-7.7 for complete hydrolysis prior to gelling is only possible with weak acids, weak alkalis, surfactant solutions and standard buffers. $\mathrm{pH}$ data in the sol- to gel-transition is measured for $\mathrm{NaOH}, \mathrm{NH}_{4} \mathrm{OH}$, soya-PC, Milli-Q water, a buffer of pH 7.0, standard solution of Tris- $\mathrm{HCl}$, phenol, acetic and nitric acid. Based on observations a $\mathrm{pH}$ dependent "gellability zone" is proposed with the sol-gel-precipitate states existing at the inside-periphery-outside of this zone.
\end{abstract}

Keywords: Ethylacetoacetate; Alkoxide; Gelpoint; Buffer

\section{Introduction}

The rapid hydrolysis rate in alkoxides is due to the presence of an electronegative alkoxy group which makes the metal atom highly prone to a nucleophilic attack. Alkoxides (of which aluminium sec-butoxide is a typical example) react rapidly and irreversibly with the $\mathrm{H}^{+}$nucleophile to give a range of hydrolysis products [1-7] dispersed in alcohol, which in this case is 2-butanol.

Chelation may help arrest a runaway alkoxide hydrolysis [8]. The replacement of a reactive alkoxy group with a less hydrolyzable entity is the key step in the chelation process. Chelating agents occupy the sites of probable water attack, chemically change the entire precursor and reduce the rate of hydrolysis. Previous studies have focused on the structures, as well as the retarded rate of hydrolysis of alkoxides using a varying chelate ratio from 0.25 to 3.0 moles of ethyl acetoacetate per mole of aluminium sec-butoxide [8-10].
The enolic form of ethyl acetoacetate contains a reactive hydroxy group that reacts readily with the alkoxide to yield a chelated molecular structure as has been extensively studied $[11,12]$.

Hence, as the molar ratio of ethyl acetoacetate increases, there is a steady replacement of the alkoxy group which constantly reduces the rate of hydrolysis and at a chelate ratio of 1:3 of alkoxide to ethyl acetoacetate, butoxy shielding is complete leading to an extremely low alkoxide reactivity. For practical purposes, the chelate ratio is maintained at about $1: 2$ to ensure low alkoxide reactivity as well as a microstructural control during processing. It must be noted that all traces of chelating agent must be removed before gelling can occur and from a microstructural viewpoint, the properties of the ceramic depend on the rate of chelate removal, i.e. the rate and nature of hydrolysis agent added to the modified precursor during its hydrolysis. Literature makes no direct mention of the importance of this step apart from suggesting an excesswater assisted hydrolysis $[13,14]$ or by a heat treatment at $260^{\circ} \mathrm{C}[15,16]$ which is the decomposition temperature of ethylacetoacetate. In an aqueous processing to achieve microstructural control, a heat cycle is imprac- 
tical hence chemical agents which have a selective, localised hydrolysis and gelling action bear special processing relevance $[17,18]$.

This communication reports the results of our experiments using $\mathrm{NaOH}, \mathrm{NH}_{4} \mathrm{OH}$, Soya-PC surfactant, Milli-Q water, a buffer of $\mathrm{pH} 7.0$, a standard solution of Tris- $\mathrm{HCl}$, phenol, acetic acid and nitric acid as hydrolysis and gelling agents. The chemical parameter measured as a result of adding the gelling agents was the $\mathrm{pH}$ measured during the sol- to gel-transition. Hydrolysis was done using these aqueous gelling agents at a constant rate of $0.1 \mathrm{ml} / \mathrm{h} / \mathrm{g}$ of alkoxide under identical conditions of temperature, humidity, sonication, chelate ratio and amount of alcohol.

\section{Experimental}

\subsection{Materials}

The aluminium sec-butoxide (ASB) used in the experiments was of $97 \%$ assay (Fluka). The iso propyl alcohol (IPA) (Fluka) with a $96 \%$ assay was dried by a $4 \mathrm{~h}$ storage in a desiccator containing calcium oxide previously heated to $800^{\circ} \mathrm{C}$. The ethyl acetoacetate (EAA) (Spectrochem) with a $96 \%$ assay was used as received. $0.025 \mathrm{M}$ $\mathrm{NaOH}$ (Spectrochem), $0.1 \mathrm{M} \mathrm{NH}_{4} \mathrm{OH}$ (Spectrochem) and a solution of $0.5 \% \mathrm{w} / \mathrm{w}$ of soya-PC $(\mathrm{BDH})$ in water were used as alkaline gelling agents on separate batches to hydrolyse and gel the chelated alumina sols. The neutral gelling agents were Milli-Q water $(18 \mathrm{M} \Omega \mathrm{cm})$ and a standard buffer solution of $\mathrm{pH}$ 7.0. The acidic gelling agents used were a $2 \%$ standard solution of Tris- $\mathrm{HCl}$, a $0.1 \mathrm{M}$ phenol solution, $0.1 \mathrm{M}$ acetic acid and $0.025 \mathrm{M}$ nitric acid. The results were compiled and compared.

\subsection{Methods}

\subsubsection{Preparation}

About $3.0 \mathrm{~g}$ of ASB were weighed out in a teflon coated, screw-capped sample bottle in a glove box containing $\mathrm{P}_{2} \mathrm{O}_{5}$ dessicant. About $15 \mathrm{ml}$ of previously dried IPA were added to it and the mix ultrasonically agitated at $18.750 \mathrm{kHz}$ at an ultrasonic power of 90 watts output for approximately $600 \mathrm{~s}$ on a Branson- 450 probe type sonicator, using a $12 \mathrm{~mm}$ diameter probe disruptor horn tip. The immersion of the probe tip was adjusted to about $2 \mathrm{~mm}$ below the liquid level in order to achieve maximum turbulence [19]. To counteract the effects of heating, and to eliminate the generation of the presently undesirable high temperature phases of aluminium hydroxide [3-5], the alcoholic alkoxide was enclosed in a cooling jacket to maintain a temperature of $28^{\circ} \mathrm{C}$ throughout the sonication period.

For the purpose of this experiment and to achieve optimal microstructural properties [20-28], the chelate ratio was kept constant at 1:2. About $1.5 \mathrm{ml}$ of EAA were added to the sonicated, alcoholic alkoxide using a previously dried pipette. Continuous sonication under $28^{\circ} \mathrm{C}$ conditions for about $1200 \mathrm{~s}$ was performed to complete the chelation process, which occurs at room temperature, as reported in the literature $[8,9,13]$. Totally, nine such batches were prepared. This first was hydrolysed with a $0.025 \mathrm{M} \mathrm{NaOH}$ solution, another with $0.1 \mathrm{M} \mathrm{NH}_{4} \mathrm{OH}$ and the third with $0.5 \% \mathrm{w} / \mathrm{w}$ of soya-PC in water so as to complete batch preparation for alkaline gelling studies. Hydrolysis was carried out upto the sonogelling point which occurred at a hydrolysing agent:alkoxide mole ratio of 2.4, 2.7 and 2.9, respectively, as determined from pilot experiments. Samples 4 and 5 were hydrolysed with Milli-Q water and the buffer solution, respectively, and the gel point in these cases was attained at a hydrolysis ratio of 3.3 and 3.5. The acid-gelling was carried out using Tris- $\mathrm{HCl}$, phenol, acetic acid and nitric acid, respectively, and the gel points as recorded from previous experiments occurred at hydrolysis ratios of 3.3, 2.9, 2.8 and 2.4, respectively. $\mathrm{pH}$ measurements indicative of reaction environments at every hydrolysis step were performed and the observations for each system were recorded and compared.

\section{Results and discussions}

$\mathrm{pH}$ measurements were performed to arrive at processing-gel point inferences. The analysis results are presented in the following sections and in Fig. 1.

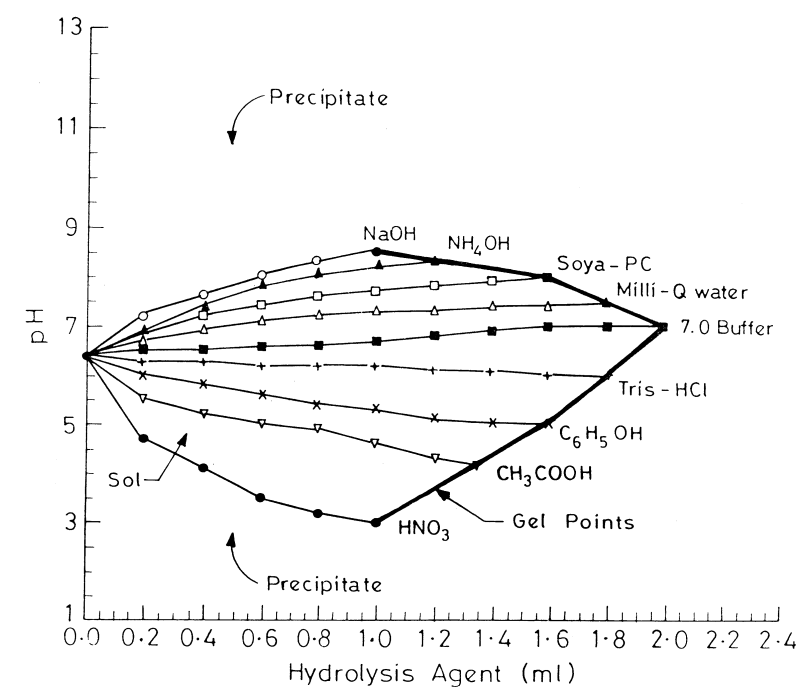

Fig. 1. A plot of $\mathrm{pH}$ observations during the sol-gel transition of chelated ASB sols hydrolysed and gelled using different gelling agents at the specified rate of hydrolysis. Gelling is likely to occur at a localised "gellability zone" which lies between a $\mathrm{pH}$ range of about 8.5 and 3.0. This plot can also help in selecting a specific hydrolysis agent which will cause the system to gel at a predetermined gel point. 
The sample which was hydrolysed with $0.025 \mathrm{M}$ $\mathrm{NaOH}$ was found to gel on the addition of $1.0 \mathrm{ml}$ of gelling agent, when it was added at the rate of $0.1 \mathrm{ml} / \mathrm{h} /$ $\mathrm{g}$ of alkoxide. Similarly, the sample hydrolysed with $\mathrm{NH}_{4} \mathrm{OH}$ was seen to sonogel at the addition of $1.2 \mathrm{ml}$ of $0.1 \mathrm{M} \mathrm{NH}_{4} \mathrm{OH}$. The third alkaline gelling sample at 1.6 $\mathrm{ml}$ of $0.5 \% \mathrm{w} / \mathrm{w}$ of soya-PC.

The sample hydrolysed with Milli-Q water was seen to sonogel at $1.8 \mathrm{ml}$ and the sample hydrolysed with the buffer solution at $2.0 \mathrm{ml}$. The samples hydrolysed with Tris- $\mathrm{HCl}$, phenol, acetic acid and nitric acid were seen to gel at 1.8, 1.6, 1.4 and $1.0 \mathrm{ml}$, respectively.

The results of $\mathrm{pH}$ changes during gelling of EAA chelated ASB are shown in Fig. 1. The baseline sample had a pH of 6.4 at the start of hydrolysis. As is by now very well understood for hydroxide formation processes, the $\mathrm{pH}$ of the system increases during hydrolysis as aluminium alkoxide converts to aluminium hydroxide.

In the alkaline system, the $\mathrm{pH}$ value of the $\mathrm{NaOH}$ hydrolysed sample was found to increase sharply to 7.2 on the addition of $0.2 \mathrm{ml}$ of $\mathrm{NaOH}$. This increase continued and at a $\mathrm{pH}$ of about 8.5 , the system was seen to gel. In the second case, $0.2 \mathrm{ml}$ of $\mathrm{NH}_{4} \mathrm{OH}$ was found to increase the $\mathrm{pH}$ to 6.9 and subsequently to 8.3 at the sonogelling point which occurred at $1.2 \mathrm{ml}$. The third sample showed a slower increase in $\mathrm{pH}$ to 6.8 on the addition of $0.5 \% \mathrm{w} / \mathrm{w}$ of soya-PC and showed a saturating $\mathrm{pH}$ value of about 8.1 at the gel point.

In the neutral hydrolysis system, the sample hydrolysed with Milli-Q water showed a very slow increase in $\mathrm{pH}$ with controlled hydrolysis from a first hydrolysis value of 6.6 to a just-before-gel point value of 7.5. The sample hydrolysed with the buffer solution showed an extremely slow increase in $\mathrm{pH}$ from 6.4 at the start of hydrolysis to 7.0 at the gel point which occurred at $2.0 \mathrm{ml}$.

In the acidic hydrolysis system, the $\mathrm{pH}$ of the Tris$\mathrm{HCl}$ hydrolysed precursor dropped extremely slowly to 6.0 at the gel point of $1.8 \mathrm{ml}$. Gelling in phenolic systems occurred at $1.6 \mathrm{ml}$ at a $\mathrm{pH}$ of 5.0. Acetic acid was found to gel the precursor at $1.4 \mathrm{ml}$ at a $\mathrm{pH}$ of 4.2 and $\mathrm{HNO}_{3}$ hydrolysis resulted in a sharp fall in $\mathrm{pH}$ to 3.0 at the gel point of $1.0 \mathrm{ml}$.

A close scrutiny of $\mathrm{pH}$ data in Table 1 , reveals that regardless of the choice of gelling media the $\mathrm{pH}$ value at the gel point lies within the region 3.0-8.5. However, from stoichiometry, 1 mole of ASB requires a minimum of 3.0 moles of water for complete hydrolysis. Hence, only the Milli-Q water, buffer, and Tris- $\mathrm{HCl}$ hydrolysed systems are completely hydrolysed before they gel. This corresponds to a $\mathrm{pH}$ range of 5.7-7.7 and on either side of this range, it is clear that though gelling is seen, hydrolysis is not complete. In $\mathrm{NaOH}$ and $\mathrm{HNO}_{3}$ hydrolysed systems which offer the $\mathrm{pH}$ limits of 8.5 and 3.0 , respectively, the extent of hydrolysis is only about $55 \%$ at the gel point. The extent of hydrolysis and its
Table 1

A comparative evaluation based on molecular stoichiometry, of the extent of hydrolysis and its dependence on the nature of hydrolysis media. In strongly acidic or alkaline hydrolysis agents, the extent of hydrolysis is very low. A neutral or near-neutral gelling agent is most preferred for high alumina yield

\begin{tabular}{|c|c|c|c|c|c|}
\hline \multirow[t]{2}{*}{ Sl no } & \multirow{2}{*}{$\begin{array}{l}\text { Hydrolysed } \\
\text { with }\end{array}$} & \multirow{2}{*}{$\begin{array}{l}\text { Gel point } \\
\text { pH }\end{array}$} & \multicolumn{2}{|c|}{ Amount for } & \multirow{2}{*}{$\begin{array}{l}\text { Hydrolysis } \\
\text { - extent, } \\
E=V_{\mathrm{g}} / V_{\mathrm{h}} \\
(\%)\end{array}$} \\
\hline & & & Gelling & Hydrolysis & \\
\hline 1 & $0.025 \mathrm{M} \mathrm{NaOH}$ & 8.5 & 1.0 & 1.8 & 55.5 \\
\hline 2 & $0.1 \mathrm{M} \mathrm{NH}_{4} \mathrm{OH}$ & 8.3 & 1.2 & 1.8 & 66.7 \\
\hline 3 & $5 \%$ Soya-PC & 8.1 & 1.6 & 1.8 & 88.3 \\
\hline 4 & Milli-Q water & 7.5 & 1.8 & 1.8 & 100.0 \\
\hline 5 & 7.0 Buffer & 7.0 & 2.0 & 1.8 & 100.0 \\
\hline 6 & $2 \%$ Tris- $\mathrm{HCl}$ & 6.0 & 1.8 & 1.8 & 100.0 \\
\hline 7 & $0.1 \mathrm{M} \mathrm{C}_{6} \mathrm{H}_{5} \mathrm{OH}$ & 5.0 & 1.6 & 1.8 & 88.3 \\
\hline 8 & $0.1 \mathrm{M} \mathrm{CH}_{3} \mathrm{COOH}$ & 4.2 & 1.4 & 1.8 & 77.2 \\
\hline 9 & $0.025 \mathrm{M} \mathrm{HNO}_{3}$ & 3.0 & 1.0 & 1.8 & 55.5 \\
\hline
\end{tabular}

dependence on the hydrolysis agent used is shown in Table 1 and it may be observed that only the weakly alkaline/neutral/weakly acidic agent gelled systems are fully hydrolysed systems which yield alumina gels, i.e. $\mathrm{Al}(\mathrm{OH})_{3}$.

A plot of $\mathrm{pH}$ vs amount of hydrolysis agent is shown in Fig. 1. It is clear that gelling in chelated alkoxides occurs only within a $\mathrm{pH}$ range of $3.0-8.5$. From a starting $\mathrm{pH}$ value of 6.4 , different hydrolysis agents bring about different gel point values and consequently a "gellability zone" based on the locii of points at which gelling occurs on choosing different hydrolysis agents, may be defined. Gels, when obtained, were found to be immobilised to the inversion of the sample bottle.

The gellability zone covers a $3.0-8.5 \mathrm{pH}$ and also indicates that beyond a hydrolysis amount of $2.0 \mathrm{ml}$, the system is not likely to gel irrespective of the choice of hydrolysis agent. From this and stoichiometric considerations, it is obvious that the possibility of having a fully hydrolysed, gelled product is restricted to precursors hydrolysed with extremely weak acids, weak alkalis and buffers so as to cover a 5.7-7.7 $\mathrm{pH}$ range.

In an effort to determine the importance of $\mathrm{pH}$ at the gel point over $\mathrm{pH}$ measurements in the entire sol-gel transition, a separate batch was hydrolysed with $0.2 \mathrm{ml}$ of $\mathrm{NaOH}$ having a $\mathrm{pH}$ of about 10.0. Alumina precipitation was found to occur. To the same batch $0.2 \mathrm{ml}$ of $\mathrm{HNO}_{3}$ of a pH of 1.8 was added in an attempt to lower the $\mathrm{pH}$ of the alkali-hydrolysed sol, reverse alumina precipitation and bring the overall $\mathrm{pH}$ to a value within the gellability zone. $\mathrm{HNO}_{3}$ was found to have no effect in reversing alumina precipitation caused by attempting to change the path into the gellability zone from a very high $\mathrm{pH}$ hydrolysis followed by a very low $\mathrm{pH}$ hydrolysis. A similar path dependence experiment first with strong acid and then with a strong alkali was also found to yield similar results. It is hence evident 
that the boundaries of the gellability zone are distinct and any change in $\mathrm{pH}$ at any stage during gelling, to values outside this zone result in an irreversible alumina precipitation.

The importance of the gellability zone in deciding upon gelling agents for alkoxides is expected to be substantial. It is likely to play a prominent role in estimating gel points and reaction conditions in novel alkoxide systems such as a mixture of aluminium and titanium isopropoxides. Also there is an entire range of microstructural studies that may be performed to evaluate small-scale changes caused by a change in hydrolysis medium. Since $\mathrm{pH}$ and gelling are both temperature dependent, the validity of the "gellability zone" at elevated or lowered temperatures, so as to favour a preferred phase formation is likely to offer further insights into processing-property relationships in alkoxide ceramics.

\section{Conclusions}

An ethyl acetoacetate chelated aluminium sec-butoxide can be hydrolysed and gelled with $0.025 \mathrm{M}$ $\mathrm{NaOH}, 0.1 \mathrm{M} \mathrm{NH}_{4} \mathrm{OH}, 0.5 \% \mathrm{w} / \mathrm{w}$ soya-PC, Milli-Q water, a pH 7.0 buffer, a solution of Tris- $\mathrm{HCl}$, phenol, acetic and nitric acids. The gel point is found to be dependent on the $\mathrm{pH}$ and occurs at a value between 3.0 and 8.5. Any increase in $\mathrm{pH}$ to outside these limiting values irreversibly precipitates alumina. A locus of gel points in systems hydrolysed with different reaction media is approximately "leaf-like" in shape and contained almost entirely within the extreme points. However, alkoxide hydrolysis may or may not be complete at the gel point. Complete hydrolysis, is achieved in the $\mathrm{pH}$ range of 5.7-7.7 and its extent is reduced as the acidity/basicity of the hydrolysis agent is increased. At a $\mathrm{pH}$ of 8.5 or 3.0 , its extent is only about $55 \%$ which implies a partially hydrolysed reaction product.

\section{References}

[1] J.J. Ebelman, Untersuchungen uber die verbindungen der borsaure und kieselsaure mit aether, Ann. 57 (1846) 319-355 (in German).

[2] J.J. Ebelman, M. Bouquet, Sur de nouvelles combinaisions de l'acide borique avec les ethers et sur l'ether sulfureux, Ann. Chim. Phys. 17 (1846) 54-73 (in French).

[3] B.E. Yoldas, Hydrolysis of aluminium alkoxide and bayerite conversion, J. Appl. Chem. Biotechnol. 23 (1973) 803-804.

[4] B.E. Yoldas, A transparent porous alumina, Ceram. Bull. 54 (1975) 286-288.

[5] B.E. Yoldas, Alumina sol preparation from alkoxides, Ceram. Bull. 54 (1975) 289-290.

[6] A.C. Pierre, D.R. Uhlmann, Gelation of aluminium hydroxide sols, J. Am. Ceram. Soc. 70 (1987) 28-32.

[7] T. Ogihara, H. Nakajima, T. Yanagawa, N. Ogata, K. Yoshida, Preparation of monodisperse, spherical alumina powders from alkoxides, J. Am. Ceram. Soc. 74 (1991) 2263-2268.
[8] R.K. Mehrotra, R.C. Mehrotra, Reactions of aluminium alkoxides with aectylacetone, benzoylacetone and ethyl acetoacetate, Can. J. Chem. 39 (1961) 795-801.

[9] J.H. Wengrovius, M.F. Garbauskas, E.A. Williams, R.C. Going, P.E. Donahue, J.F. Smith, Aluminium alkoxide chemistry revisited: synthesis, structures and characterization of several aluminium alkoxide and siloxide complexes, J. Am. Chem. Soc. 108 (1986) 982-987.

[10] C. Sanchez, L. Livage, M. Henry, J. Babonneau, Chemical modification of alkoxide precursors, J. Non-Cryst. Solids 100 (1988) 65-71.

[11] H. Schmidt, Chemistry of material preparation by the sol-gel process, J. Non-Cryst. Solids 100 (1988) 51-57.

[12] F. Babonneau, L. Coury, J. Livage, Aluminium sec-butoxide modified with ethylacetoacetate: an attractive precursor for the sol-gel synthesis of ceramics, J. Non-Cryst. Solids 121 (1990) 153-157.

[13] R. Nass H. Schmidt, in: H. Hausner, G.L. Messing, S. Hirano (Eds.), Proc. 2nd Int. Conf. on Ceramic Powder Processing Science, October 1988, Deutsche Keramische Gesellschaft, Cologne, 1989, pp. 69-73.

[14] R. Nass, R.J. Schmidt, Synthesis of an alumina coating from chelated aluminium alkoxide, J. Non-Cryst. Solids 121 (1990) 329-333.

[15] T. Yogo, H. Iwahara, Synthesis of alpha-alumina fibre from modified aluminium alkoxide precursor, J. Non-Cryst. Solids 100 (1992) 215-219.

[16] T. Heinrich, F. Raether, H. Marsmann, Growth and structure of single phase mullite gels from chelated aluminium alkoxides and alkoxysilanes, J. Non-Cryst. Solids 168 (1994) 14-22.

[17] K. Tadanaga, T. Iwami, N. Tohge, T. Minami, Precursor structure and hydrolysis-gelation process of $\mathrm{Al}(\mathrm{O}-\mathrm{sec}-\mathrm{Bu})_{3}$ modified with ethylacetoacetate, J. Sol-Gel Sci. Tech. 3 (1994) 5-10.

[18] L.B. Coury, F. Babonneau, J. Livage, Investigation of the sol-gel chemistry of ethylacetoacetate modified aluminium sec-butoxide, J. Sol-Gel Sci. Tech. 3 (1994) 157-168.

[19] R. Barenholz, D. Gibbes, B.J. Litman, J. Goll, T.E. Thompson, F.D. Carlson, A simple method for the preparation of homogeneous phospholipid vesicles, Biochemistry 16 (1977) 2806-2808.

[20] M. Haridas, Microstructure development in ceramic precursors: experimental studies, Doctoral Dissertation, Indian Institute of Technology, Bombay, 1997.

[21] M.M. Haridas, J.R. Bellare, A method to prepare highly transparent aluminium hydroxide gels from alkoxides, Indian patent application 487/BOM/95, 1995.

[22] M.M. Haridas, J.R. Bellare, A method to produce Nordstrandite from aluminium alkoxides, Indian patent application 488/BOM/ 95, 1995.

[23] M.M. Haridas, A. Menon, N. Goyal, S. Chandran, J.R. Bellare, Cryogenic-scanning electron microscopy as a technique to image sol to gel transformation in chelated alkoxide systems, Ceramics International 22 (1996) 155-159.

[24] M.M. Haridas, J.R. Bellare, Microstructure evolution in chelated partially hydrolysed alumina sols during sonogelling, Bull. Mater. Sci. 20 (1997) 49-66.

[25] M.M. Haridas, J.R. Bellare, Chemical synthesis of optical grade ceramic precursors: a spectrophotometric approach for analysis, Ceramics International, 24 (1998) 415-420.

[26] M.M. Haridas, J.R. Bellare, Sonogelling in chelated boron alkoxides and imaging of "wet" boria microstructures using cryoSEM, J. Mater. Charact., in press.

[27] M.M. Haridas, J.R. Bellare, Time and temperature based gellability zones in modified titanium alkoxide sols, Ceramics International, 25 (1999) 601-606.

[28] M.M. Haridas, J.R. Bellare, Differences in particle sizes measured by cryo-SEM and quasi-elastic light scattering for certified polystyrene latex standards, Colloids and Surfaces, A133 (1998) 165-171. 